Proceedings of XIX International Scientific Conference "New Technologies and Achievements in Metallurgy, Material Engineering, Production Engineering and Physics", Częstochowa, Poland, June 7-8, 2018

\title{
Silicon Addition Influence on Properties of Anodised Al-Si Alloy Surface
}

\author{
K. Labisz*, J. Konieczny, Ł. Wierzbicki, J. ĆWiek And J. MŁyńczak \\ Silesian University of Technology, Faculty of Transport, Department of Railway Transport, \\ Z. Krasińskiego 8, 40-019 Katowice, Poland
}

\begin{abstract}
This work presents the influence of the anodizing method and parameters on the properties and microstructure of the anodic layer produced on AlSi8 and AlSi9Cu3 cast aluminium alloys, in particular the effect on size and morphology of primary Si precipitates and the homogeneity of the resulting oxide coating. For investigations there were applied light microscope techniques, moreover hardness and wear resistance was examined in order to evaluate the obtained surface quality. The microstructure of the obtained surface layer was analysed by taking into account the primary silicon precipitates. The results of the hardness and abrasive wear test also show the influence of anodizing and electrolyte parameters on the structure and properties of the tested aluminium alloys. In case of the AlSi9Cu3 alloy the obtained alumina layer is of lower thickness - $13.3 \mu \mathrm{m}$, about $50 \%$ less compared to the AlSi8 one, however the AlSi8 layer is more homogeneous and more uniform. The results of the wear test show that both anodised alloys show ca. $35 \%$ lower mass loss compared to non-anodized alloys, so structure of the $\mathrm{Al}_{2} \mathrm{O}_{3}$ layer increases the abrasion resistance.
\end{abstract}

DOI: 10.12693/APhysPolA.135.143

PACS/topics: anodisation, aluminium alloys, microstructure, surface layer, wear resistance

\section{Introduction}

Anodizing is an electrochemical conversion process existing since the last century. Several metals are capable of being anodized including aluminium, magnesium, titanium, and tantalum. Anodized aluminium is used in many applications due to its low cost, aesthetic qualities, and ideal mechanical properties. It is also used because of its thermal properties designed for producing of technical means of transport. This material can be coated also on other engineering materials with a possible usage of these coatings for producing of cooling cabins on vehicles allowing us to reduce fuel for maintain of given temperature. It has an important influence on transport quality and quality costs [1-8].

Unlike most protective coatings, anodizing permanently changes the outer structure of the metal. When aluminium is exposed to air it naturally develops a thin aluminium oxide film that seals the aluminium from further oxidation. The anodizing process makes the oxidized surface much thicker, up to several micrometers. The hardness of the anodized aluminium oxide coating is very hard, enhancing the abrasion resistance of the aluminium. The achieved depth of the oxide layer improves the corrosion resistance of the aluminium, while making cleaning of the surface easier. The porous nature (Fig. 1) of particular types of anodizing makes it possible to dye the aluminium a variety of colours, making it more attractive [9-13].

*corresponding author; e-mail: krzysztof.labisz@polsl.pl

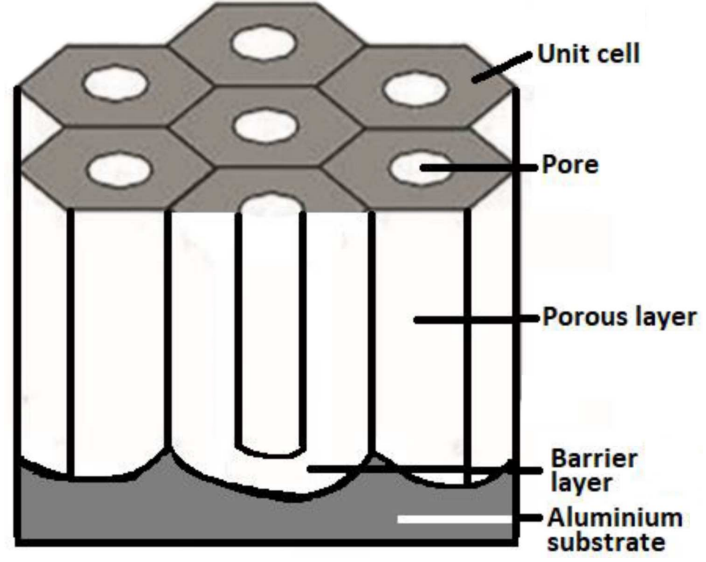

Fig. 1. Hexagonal cell structure of the porous aluminium oxide layer produced on the aluminium substrate during anodizing.

For anodizing there are used different aluminium alloys, also these used in this investigations: AlSi8 and AlSi9Cu3. Higher purity alloys are always preferred for anodizing, anodize better, producing better finishes. Alloying elements such as copper or silicon do not anodize and leave microscopic voids in the aluminium oxide film. Since the anodizing process converts the aluminium to aluminium oxide to form the anodized finish, higher purity aluminium will yield a denser and harder layer of aluminium oxide. High concentrations of some alloying elements will also affect the surface finish and colour of the anodized finish and will reduce the effectiveness of the sealing process causing reduced corrosion and wear resistance and decreasing fade resistance in dyed parts [14-18]. 
Cast aluminium parts in general will not anodize as well because of their tendency toward porosity. Pores do not anodize and contribute to the same type of problem that highly alloyed aluminium parts encounter. Good high-density castings without porosity will anodize with good results. The process of electrochemical conversion of the surface of an aluminium part to aluminium oxide causes a dimensional growth of the layer during anodizing. Aluminium oxide occupies about twice the volume as that of raw aluminium, including the intermetallic phases present in the basic alloy, for this reason it is important to investigate the influence not only of the anodizing parameters but also on the alloy chemical composition and on the structure and properties of the obtained final product [19-25].

The main goal of this work is to analyse the influence and suitability of proper chemical composition and anodizing parameters for optimal alumina layer in terms of layer homogeneity, hardness, and wear resistance.

\section{Materials and investigation procedure}

\subsection{Material}

Investigations were carried out on the AlSi8 an well as AlSi9Cu3 aluminium cast alloys, used for bodies and housings of diverse constructions (Fig. 2). For both AlSi8 as well as AlSi9Cu3 alloys the high pressure casting method was used. The chemical composition of these alloys is presented in Table I.
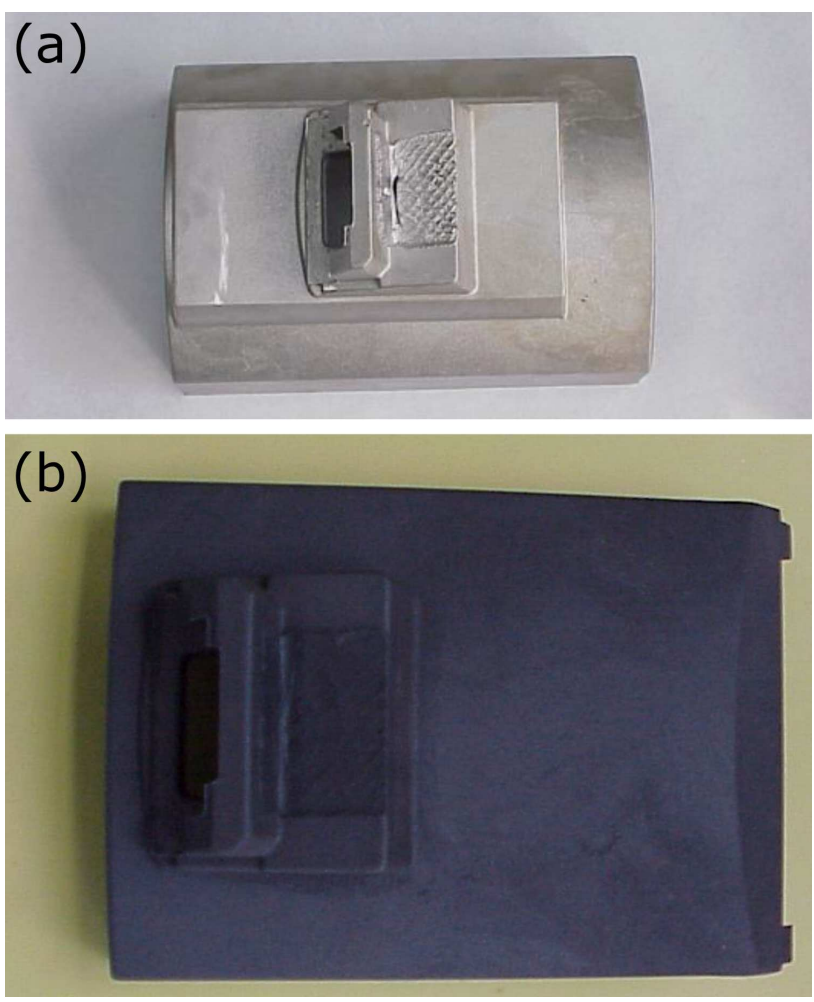

Fig. 2. Housing element using for anodisation: (a) non-anodised, (b) anodised.
TABLE I

Chemical composition of the investigated cast aluminium alloys AlSi8 and AlSi9Cu3.

\begin{tabular}{c|c|c|c|c|c|c|c}
\hline \hline \multirow{2}{*}{$\begin{array}{c}\text { Alloy } \\
\text { type }\end{array}$} & \multicolumn{6}{|c}{ Elements concentration [mass\%] } \\
\cline { 2 - 8 } & $\mathrm{Si}$ & $\mathrm{Mg}$ & $\mathrm{Cu}$ & $\mathrm{Mn}$ & $\mathrm{Fe}$ & $\mathrm{Zn}$ & $\mathrm{Al}$ \\
\hline AlSi8 & 7.8 & 0.03 & 0.03 & 0.13 & 0.3 & 0.1 & bal. \\
AlSi9Cu3 & 8.12 & 0.26 & 2.89 & 0.24 & 0.68 & 0.85 & bal.
\end{tabular}

TABLE II

Anodizing parameters applied for the investigated aluminium alloys.

\begin{tabular}{l|c}
\hline \hline \multicolumn{1}{c|}{ Parameter } & Value \\
\hline electrolyte & $\mathrm{H}_{2} \mathrm{SO}_{4}$ with a conc. $295 \div 315 \mathrm{~g} / \mathrm{l}$ \\
temperature & $-4 \div 2{ }^{\circ} \mathrm{C}$ \\
& $2 \mathrm{~A} / \mathrm{dm}^{2}$ during $0.25 \mathrm{~s}$, \\
pulse current & $1 \mathrm{~A} / \mathrm{dm}^{2}$ during $0.1 \mathrm{~s}$ \\
conc. of $\mathrm{Al}$ ions & $6 \div 9 \mathrm{~g} / 1$
\end{tabular}

For anodising two housing parts were selected, the AlSi9Cu3 high pressure cast alloy and AlSi8 high pressure cast alloy. Technological parameters of the anodizing process are shown in Table II. The anodised elements of the AlSi9Cu3 as well as AlSi8 high pressure alloy are showed in Fig. 2a and b.

\subsection{Methods}

To determine the influence of a kind of electrolyte onto homogeneity of pores in the oxides layer at the same conditions, the samples of AlSi9Cu3 alloy were put under anodic treatment in the presence of the following electrolytes: $3 \% \mathrm{H}_{2} \mathrm{C}_{2} \mathrm{O}_{4}, 4 \% \mathrm{H}_{3} \mathrm{PO}_{4}, 4 \% \mathrm{H}_{2} \mathrm{SO}_{4}, 3 \% \mathrm{CrO}_{3}$.

For investigations of the microstructure the following tests were carried out:

- Samples were cut on saw using the Discotom-2 saw model supplied by Struers.

- The specimens were mounted in Resin 4 using the press LaboPress-3 supplied by Struers.

- Grinding was performed on SiC paper (size 80, 120, 180, 240, 320, 400, 600) using the grinding machine model Rotor-2 supplied by Knuth.

- Polishing was performed using the polishing machine model RotoPol-31 (with RotoForce-4, Multidoser and Rotocom) all supplied by Struers. Polishing steps were according to the Metalog A Methods provide by Struers.

- The optical micrographs were obtained using a light microscope (model BX60M supplied by Olympus), equipped with digital camera. The program "analySIS" was used to capture the photos.

- Wear test investigation: abrasive wear tests were performed using the tester model ABR-8251 supplied by TCD Teknologi ApS. The tests were 
done according to the specifications of the standard ISO 8251, as follows: load, $4.9 \mathrm{~N}$ (500 g); slide velocity, 40 cycles/min; abrasive wheel steps, $400 \mathrm{step} /$ rotation; wear area, $12 \times 30 \mathrm{~mm}^{2}$.

Conditions for the abrasive wear tests: humidity, $63 \%$; temperature, $23^{\circ} \mathrm{C}$; replicates, 2 .

Wear resistance is expressed in mass loss [mg]. Each sample was weighed before and after the wear test. Data presented in Table III are average values.

TABLE III

Thickness of the alumina layer for the non-anodised (A) and anodised (B) material.

\begin{tabular}{l|c|c|c|c}
\hline \hline \multirow{2}{*}{ Parameters } & \multicolumn{4}{|c}{ Alloy } \\
\cline { 2 - 5 } & \multicolumn{2}{|c}{ AlSi8 } & \multicolumn{2}{c}{ AlSi9Cu3 } \\
\cline { 2 - 5 } & $\mathrm{A}$ & $\mathrm{B}$ & $\mathrm{A}$ & $\mathrm{B}$ \\
\hline average & $0.32 \mu \mathrm{m}$ & $26.3 \mu \mathrm{m}$ & $0.48 \mu \mathrm{m}$ & $13.3 \mu \mathrm{m}$ \\
stand. dev. & $0.18 \mu \mathrm{m}$ & $9.5 \mu \mathrm{m}$ & $0.05 \mu \mathrm{m}$ & $3.8 \mu \mathrm{m}$
\end{tabular}

\section{Investigation results}

The microstructure of the material used for anodisation - presented in Fig. 3a and $\mathrm{b}$ - reveals the presence of needle shaped primary silicon precipitates $\operatorname{Si} \alpha$ (Fig. 3c and d), of similar size for the AlSi8 and AlSi9Cu3 alloy, the mean value of the length is of $c a .100 \mu \mathrm{m}$, with a width of $c a$. $5 \mu \mathrm{m}$. However, the amount is higher in case of the AlSi9Cu3 alloy because of a higher Si content in the chemical composition of the alloy.

Metallographic observations of the surface layer crosssection of the anodized material show that the structure of the $\mathrm{Al}_{2} \mathrm{O}_{3}$ anodic layer presented in Fig. $3 \mathrm{f}(\mathrm{AlSi} 9 \mathrm{Cu} 3)$ exhibits much higher homogeneity obtained by pore anodization compared to that shown in Fig. 3e (AlSi8). There has also been found an influence on the amount and size of discontinuities. The structure shown in Fig. 3e presents only a low amount of small pores and their arrangement is more regular. In general, it can be stated that a higher amount of silicon is not suitable for achievement of a alumina layer which is homogeneous, but on the other hand is more tightly adjacent to the aluminium substrate. For the AlSi8 alloy the silicon amount is slightly lower, but the layer itself is more homogeneous, much more thicker however the layer adheres not optimally to the substrate, so for applications where the substrate should be protected against external factors, as well as for food industry, however where pure mechanical protection is required, it is the better option compared to the AlSi9Cu3 alloy.

The thickness measurements reveal the value of $13.3 \mu \mathrm{m}$ for the AlSi9Cu3 alloy and $26.3 \mu \mathrm{m}$ for the AlSi8 alloy, also the standard deviation (Table III), confirms that the layer obtained in case of the AlSi9Cu3 alloy is more uniform and homogeneous.

Based on the analysis of the abrasive wear test it was found that anodic treatment in general increases the abrasive wear resistance of the material. In general,
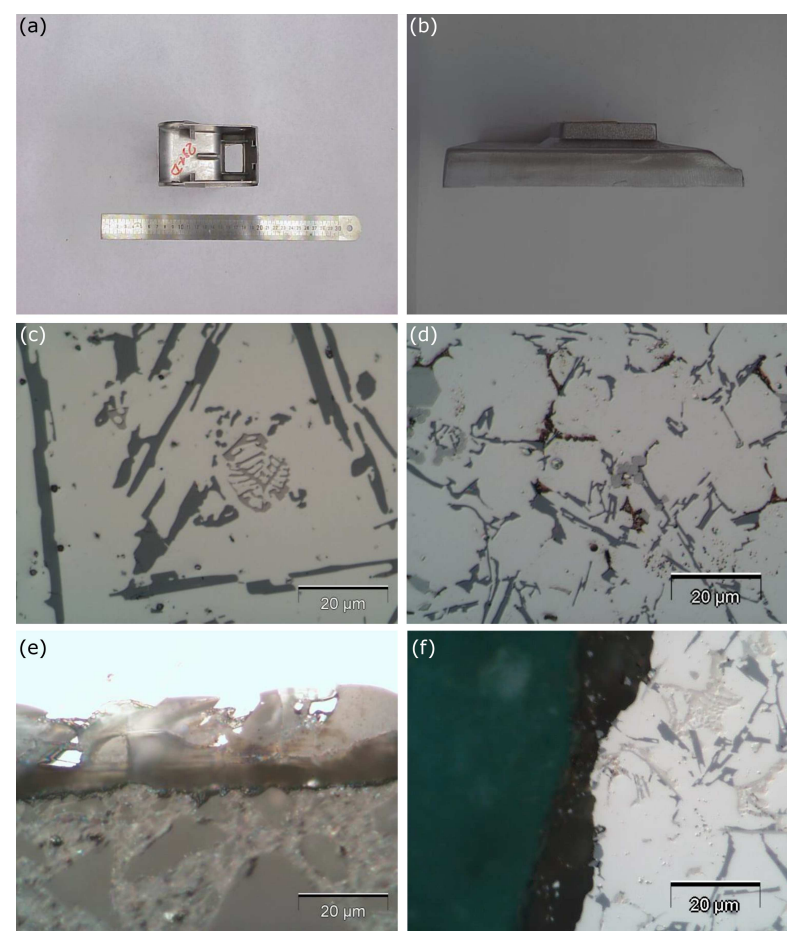

Fig. 3. Elements used for anodising: (a) AlSi8, (b) AlSi9Cu3; microstructure of the: (c) AlSi8 and (d) AlSi9Cu3 cast aluminium alloy used for anodising. Cross-section of the obtained surface layer after anodising: (e) AlSi8 and (f) AlSi9Cu3.

the results are very similar, however the highest wear resistance was achieved for anodic layer with high thickness of $26.3 \mu \mathrm{m}$ for the AlSi8 alloy. A partial removal of the coat was observed for all casts produced in high pressure die casting, where thickness of the coat is lower than $10 \mu \mathrm{m}$. The samples made of AlSi9Cu3 alloy present lower loss in mass, both for the anodised and non-anodised AlSi8 and AlSi9Cu3 alloy.

The results presented in Figs. 4 and 5 indicate that anodised samples of the AlSi8 and AlSi9Cu3 alloy are characterised by a lower loss in mass in comparison to the non-samples anodised by $72 \%$ and $83 \%$, respectively. Also the hardness value is higher for the anodised elements, especially for the AlSi9Cu alloy with a value of $91 \mathrm{HRF}$, ca. 10\% higher compared to the AlSi8 alloy.

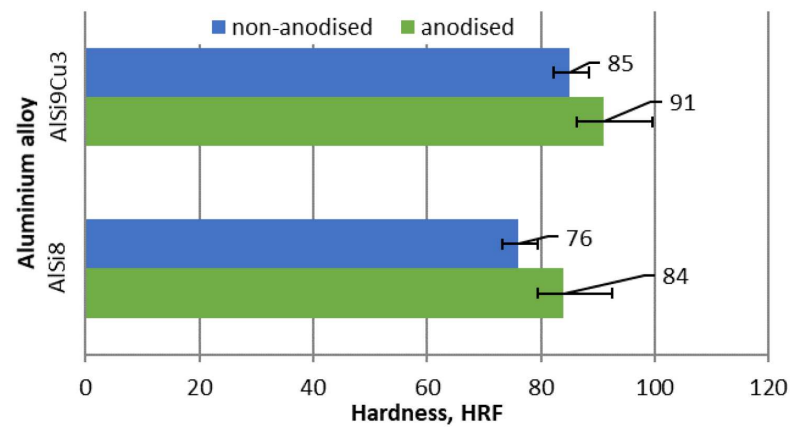

Fig. 4. Hardness measured of the anodised and nonanodised AlSi8 and AlSi9Cu3 alloys. 


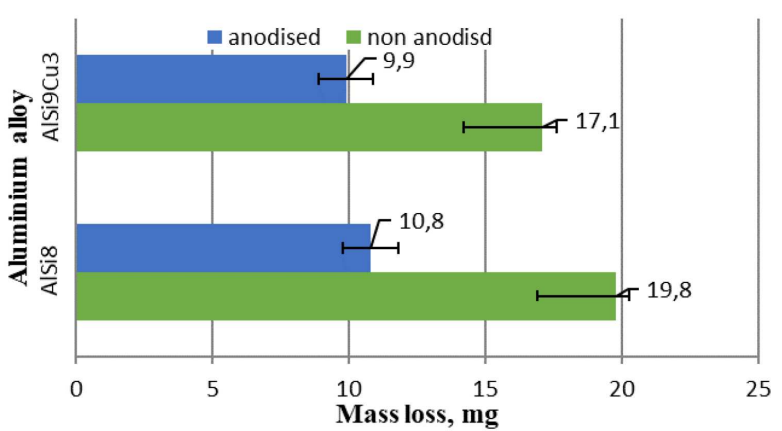

Fig. 5. Mass loss measured during the wear test of the anodised and non-anodised $\mathrm{AlSi} 8$ and $\mathrm{AlSi} 9 \mathrm{Cu} 3$ alloys.

\section{Conclusions}

Based on the performed investigations the following issues can be pointed out:

- The investigated AlSi8 and AlSi9Cu3 cast aluminium alloys are in general suitable for anodic oxidation. In case of the AlSi9Cu3 alloy the obtained alumina layer is of lower thickness $(13.3 \mu$ $\mathrm{m})$ compared to the AlSi8 alloy $(26.3 \mu \mathrm{m})$, however the AlSi8 layer is of higher thickness homogeneity and more uniform, but reveals more pores.

- The test results of the wear investigation results show that anodised alloys, both AlSi8 and AlSi9Cu3, show less mass loss compared to nonanodized alloys. It can be seen that structure of the layer affects the abrasion resistance.

- Concerning hardness measurement it can be found that the hardness value does not corresponds to the thickness, but to the structure of the obtained layer. More homogeneous layer, in terms of lack of pores, influences more the layer hardness as the total layer thickness, the quality goes before the quantity.

\section{References}

[1] L.E. Fratila-Apachitei, F.D. Tichelaar, G.E. Thompson, H. Terryn, P. Skeldon, J. Duszczyk, L. Katgerman, Electrochim. Acta 49, 3169 (2004).

[2] I. Vrublevsky, V. Parkoun, J. Schreckenbach, G. Marx, Appl. Surf. Sci. 220, 51 (2003).

[3] I. Vrublevsky, V. Parkoun, V. Sokol, Appl. Surf. Sci. 222, 215 (2004).
[4] M. Gwoździk, Z. Nitkiewicz, Archiv. Civil Mech. Eng. 14, 335 (2014).

[5] M. Gwoździk, Z. Nitkiewicz, Opt. Appl. 39, 853 (2009).

[6] L.A. Dobrzanski, R. Nowosielski, J. Konieczny, J. Wyslocki, A. Przybył, J. Mater. Process. Technol. 157, 669 (2004).

[7] P. Snopinski, T. Tanski, K. Labisz, S. Rusz, P. Jonsta, M. Król, Int. J. Mater. Res. 107, 637 (2016).

[8] S. Juchim, Przeglad Elektrotechniczny 89, 155 (2013).

[9] A. Posmyk, A. Bogdan-Włodek, Zeszyty Naukowe. Transport/Politechnika Ślaska 87, 21 (2015).

[10] M. Krupinski, B. Krupinska, Z. Rdzawski, K. Labisz, T. Tanski, J. Therm. Anal. Calorim. 120, 1573 (2015).

[11] M. Piec, L.A. Dobrzanski, K. Labisz, E. Jonda, A. Klimpel, Adv. Mater. Res. 15-17, 193 (2007).

[12] J. Konieczny, K. Labisz, M. Polok-Rubiniec, A. Wlodarczyk-Fligier, Archiv. Metall. Mater. 61, 991 (2016).

[13] J.B. Ferguson, B.F. Schultz, J.C. Mantas, H. Shokouhi, P.K. Rohatgi, Metals 4, 314 (2014).

[14] L. Wang, M. Makhlouf, D. Apelian, Int. Mater. Rev. 40, 221 (1995).

[15] H. Fredriksson, U. Åkerlind, Solidification and Crystallization Processing in Metals and Alloys, Wiley, Chichester 2012.

[16] D.M. Stefanescu, Science and Engineering of Casting Solidification, Kluwer Academic, New York 2002.

[17] E. Nyama, K. Anzai, T. Funakubo, S. Hiratsuka, J. Mater. Process. Technol. 63, 779 (1997).

[18] D.K. Dwivedi, R. Sharma, A. Kumar, Int. J. Cast Met. Res. 19, 275 (2006).

[19] H. Elzanaty, Int. J. Res. Eng. Technol. 2, 4954 (2014).

[20] J.G. Kaufman, E.L. Rooy, Aluminum Alloy Castings: Properties, Processes and Applications, ASM Int., Materials Park (OH) 2004.

[21] H.O. Santos, F.M. Reis, C.T. Kunioshi, J.L. Rossi, I. Costa, Mater. Res. 8, 155 (2005).

[22] C.H. Cáceres, M.B. Djurdjevic, T.J. Stockwell, J.H. Sokolowski, Scr. Mater. 40, 631 (1999).

[23] A. Couture, AFS Int. Cast Met. J. 6, 9 (1981).

[24] Z. Łukasik, A. Kuśmińska-Fijałkowska, J. Kozyra, Sci. J. Silesian Univ. Technol. Series Transport 95 , 109 (2017).

[25] I. Mańka, A. Mańka, Sci. J. Silesian Univ. Technol. Series Transport 93, 91 (2016). 